\title{
Extrativismo e Abordagem Sistêmica
}

\section{Refletions Extractivism and Systemic Approach}

Camila Vieira da Silva - Doutora em Desenvolvimento Rural pela Universidade Federal do Rio Grande do Sul (UFGRS); pós-doutoranda em Desenvolvimento Rural pela UFGRS, Porto Alegre-RS. E-mail: camivs@gmail.com

Lovois de Andrade Miguel - Ph.D. em Agronomia pelo Institut National Agronomique Paris. Pós-doutorado pela AgroParis'Tech. E-mail: lovois@ufrgs.br.

\section{Resumo}

Os conceitos usualmente utilizados para caracterizar o sistema de produção agrícola em nível das Unidades de Produção Agrícola apresentam limitações e restrições para descrever, compreender e analisar as atividades de extrativismo. $\mathrm{O}$ extrativismo, visto pela ótica da abordagem sistêmica, pode permitir uma melhor compreensão desta atividade, caracterizada por um grande número de interconexões e uma elevada complexidade, tanto em nível socioeconômico, agronômico, como ambiental. Inicialmente, cabe salientar que foi verificada uma grande heterogeneidade de termos, conceitos e noções correlacionados ao extrativismo, em sua maioria, fundamentados em uma visão pontual e disciplinar. Pode-se constatar que tanto o extrativismo vegetal como o extrativismo animal possuem conhecimentos e diversos graus de intencionalidades associados à manutenção e promoção do estoque das espécies exploradas. O extrativismo, enquanto ação antrópica direta ou indiretamente realizada sobre as espécies animais e vegetais, não pode ser compreendida se descontextualizada ou isolada do macrossistema no qual ela opera e encontra as justificativas de sua existência. Deste modo, considerou-se que os sistemas de cultivo e de criação devem ser entendidos como gradientes que vão desde o cultivo e criação de espécies domesticadas, aliadas às práticas agrícolas convencionais, até o extrativismo vegetal e animal, com práticas de manutenção e promoção de determinadas espécies.

\section{Palavras-chave}

Abordagem Sistêmica. Extrativismo. Sistema de cultivo. Sistema de Produção.

\begin{abstract}
The concepts commonly used to characterize the agricultural production system in terms of Agricultural Production Units have limitations and restrictions to describe, understand and analyze the Extractivism activities. Extractivism, seen from the perspective of systemic approach can provide a better understanding of this activity, characterized by a large number of interconnections and high complexity, both in socio-economic, agronomic and environmental levels. Initially, it should be noted that there was a great heterogeneity of terms, concepts and notions related to Extractivism, mostly being grounded in a punctual discipline and vision. It can be seen that both gathering and hunting have varying degrees of knowledge and intentions associated with maintaining and promoting the stock of exploited species. Extractivism, the anthropogenic activities directly or indirectly conducted on plant and animal species, cannot be understood if decontextualized and isolated from the macro system in which it operates and in which it finds its justification for existence. In this way, it was considered that the system of farming and breeding should be understood as gradients ranging from the farming and breeding of domesticated species allied to conventional agricultural practices to the plant gathering and animal hunting with maintenance and promotion practices of certain species.
\end{abstract}

\section{Keywords}

Systemic Approach. Extractivism. Cropping System. Farming System. 


\section{INTRODUÇÃO}

O extrativismo, enquanto atividade humana caracterizada por um grande número de interconexões, faz parte de um conjunto de ações realizadas no âmbito de suas atividades produtivas e, por conseguinte, estreitamente imbricadas a diferentes questões socioeconômicas, agronômicas e ambientais. $\mathrm{O}$ extrativismo é, portanto, uma construção social realizada ao longo de gerações, promovendo acúmulos de saberes, constituindo-se em um objeto de estudo complexo. Constata-se, tanto em nível teórico quanto em nível aplicado, uma reflexão insuficiente acerca do extrativismo, sob a ótica da abordagem sistêmica. Nos últimos anos, a crescente utilização do conceito de Sistema de Produção em áreas florestais tem imposto à pesquisa científica a necessidade de refletir sobre o extrativismo à luz desta abordagem teórico-metodológica.

A reflexão acerca da utilização do enfoque sistêmico como instrumento de análise do extrativismo demanda a explicitação de alguns pressupostos. Para tanto, este artigo está divido em cinco partes. A primeira versará sobre a Abordagem Sistêmica no âmbito das Ciências Agrárias, no caso, a Teoria de Sistemas Agrários; a segunda versa sobre os conceitos de extrativismo; a terceira trata do extrativismo vegetal e do sistema de produção. $\mathrm{Na}$ quarta parte serão expostos exemplos sobre o extrativismo animal; e na quinta parte discorrer-se-á sobre uma possível contribuição para a abordagem teórico-metodológica em questão.

\section{A TEORIA DE SISTEMAS AGRÁRIOS}

A utilização do enfoque sistêmico para estudar a realidade agrária é uma perspectiva recente. Iniciou-se na metade do século XX, e está intimamente ligada à necessidade de abordar dois fenômenos distintos. O primeiro relacionado à aceleração do processo de modernização e intensificação da agricultura, e o segundo concernente às críticas acerca das estratégias de desenvolvimento baseadas na execução de projetos reducionistas e disciplinares, direcionadas a agricultores, com escassos recursos físicos e financeiros, que normalmente não atingiam os resultados propostos (MAZOYER; MIGUEL, 2009).

No campo das ciências agrárias, o enfoque sistêmico tem evidenciado que a sua utilização torna-se muito importante, devido à complexidade dos sistemas organizados e manejados pelo homem. Assim, a necessidade de utilizar o enfoque sistêmico em estudos relacionados ao extrativismo justifica-se porque esta é uma atividade humana caracterizada por um grande número de interconexões. O 
extrativismo faz parte do conjunto de ações humanas realizadas no âmbito das atividades produtivas e, por conseguinte, estreitamente imbricadas a estas, bem como às questões de ordem socioculturais. Esta relação é uma construção social que ocorreu no passar do tempo, gerando um acúmulo de saberes, e fazendo do extrativismo um objeto de estudo complexo.

Além disso, outro pensamento da teoria sistêmica que auxilia nos estudos sobre extrativismo é a noção de que o ambiente é, por si, um sistema vivo e capaz de adaptação e mudança (MORIN, 2005). Este entendimento auxilia na percepção da relação do extrativista com o espaço no qual ele realiza o extrativismo. O homem não apenas extrai o que lhe é útil na natureza, mas também desenvolve uma relação em que as suas ações moldam um novo ambiente, e este gera uma modificação ou adaptação por parte do ser humano. Esta lógica aponta outro modo de perceber a relação sociedade-natureza. Uma das teorias que se desdobram da abordagem sistêmica, e que nos permite estudar o extrativismo à luz das suas noções e os conceitos, é a Teoria de Sistemas Agrários (MAZOYER; ROUDART, 2010).

Para Mazoyer e Roudart (2010), a Teoria de Sistemas Agrários é um instrumento intelectual que permite apreender a complexidade das diversas formas de agricultura, como também dar conta das suas transformações históricas e diferenciações geográficas. Cabe salientar que a Teoria de Sistemas Agrários não tem por função esgotar a riqueza da história e da geografia agrárias. Esta constata as formas de agricultura mais correntes e duráveis, mas não se detém nas particularidades de cada uma delas.

O Sistema Agrário, segundo Mazoyer, consiste em um modo de exploração do meio historicamente constituído e durável, e um conjunto de fatores de produção adaptado às condições bioclimáticas de um determinado espaço, que responde às condições e às necessidades sociais do momento. E, para o entendimento do que é um Sistema Agrário, faz-se necessário um esforço de compreensão em duas vertentes. A primeira, consiste na observação da agricultura como um objeto real do conhecimento e, em segundo plano, a abstração um conjunto de conhecimentos que gere um objeto teórico que una percepção e reflexão.

A ampliação das observações em um determinado sistema agrário leva à constatação de que existe uma classificação em um número finito de categorias, de formas de agricultura, tanto no tempo quanto no espaço. Tais categorias são sistemas de objetos complexos. Para a análise sistêmica desses objetos, devese compreender o seu funcionamento como uma combinação de funções independentes e complementares. Desta forma, a análise de sistemas agrários 
decompõe o objeto de estudo em dois subsistemas principais: o ecossistema cultivado e o sistema social produtivo - e estuda as suas organizações e funcionamento, bem como as suas inter-relações (MAZOYER; ROUDART, 2010).

$\mathrm{O}$ ecossistema cultivado corresponde à forma como se organizam os constituintes físicos, químicos e biológicos de um Sistema Agrário (SILVA NETO; BASSO, 2005), e possui vários subsistemas complementares, como os sistemas de cultivo e de criação. Cada um desses subsistemas é organizado, cuidado e explorado de maneira particular, a fim de satisfazer às necessidades do agricultor e da sua família. Ademais, o ecossistema cultivado exerce um funcionamento pelo qual ele se renova.

O sistema social produtivo é composto pela família do agricultor (força de trabalho, conhecimento e saber-fazer), pelos meios inertes (instrumentos e equipamentos) e pela matéria viva (plantas cultivadas e animais domésticos). São componentes com os quais os agricultores desenvolvem "[...] as atividades de renovação e de exploração da fertilidade do ecossistema cultivado, a fim de satisfazer direta ou indiretamente suas próprias necessidades [...]" (MAZOYER; ROUDART, 2010, p. 73). Portanto, um sistema agrário resulta da combinação das seguintes variáveis essenciais (MAZOYER, 1987, apud INCRA/FAO, 1999, p. 20):

a) o meio cultivado - o meio original e as suas transformações históricas;

b) os instrumentos de produção - as ferramentas, as máquinas e os materiais biológicos, como as plantas cultivadas, os animais domésticos etc.;

c) a força de trabalho social;

d) o modo de "artificialização" do meio - do qual resulta a reprodução e a exploração do ecossistema cultivado;

e) a divisão social do trabalho entre a agricultura, o artesanato e a indústria;

f) os excedentes agrícolas e as relações de troca com os outros atores sociais;

g) o conjunto de ideias e instituições que permitem assegurar a reprodução social.

Além do conceito de Sistema Agrário, tanto Apollin e Eberhart (1999) quanto Mazoyer e Miguel (2009) mencionam que a análise do meio rural, pela Teoria dos Sistemas Agrários requer a utilização de diversos conceitos de cunho sistêmico. Esses conceitos de abrangência micro visam descrever e caracterizar os processos produtivos e técnicos concernentes a uma unidade de produção agrícola (UPA). 
Unidade de produção agrícola é um sistema composto de um conjunto de elementos em interação (sistemas de cultivo e/ou criação e/ou transformação), influenciada pelos objetivos do agricultor/produtor rural e sua família (sistema social), aberta e em interação com o meio externo (econômico, ambiental e humano). Assim, a UPA pode ser concebida como o objeto resultante da interação do sistema social com o sistema de produção (MAZOYER; MIGUEL, 2009, p. 24).

Os conceitos de abrangência micro, que normalmente são utilizados no diagnóstico agrário, são: os sistemas de produção, de cultivo e de criação. $O$ sistema de cultivo consiste na descrição dos cultivos e seus itinerários técnicos realizados em nível de parcela, e seguindo uma ordem e sucessão conhecida e recorrente (SEBILLOTE, 1990). O sistema de criação pode ser definido pela combinação dos diferentes modos de condução aplicados às diferentes categorias de uma espécie animal (LANDAIS; LHOSTE; MILLEVILLE, 1987).

Segundo Dufumier (1996), um elemento fundamental para a compreensão do modo de exploração do meio ao nível de uma UPA é o conceito de Sistema de Produção. O sistema de produção é definido por este autor como uma combinação (no tempo e no espaço) dos recursos disponíveis para a obtenção da produção vegetal e animal. O sistema de produção também pode ser concebido como uma combinação mais ou menos coerente de diversos subsistemas produtivos.

Analisar um sistema de produção na escala dos estabelecimentos agrícolas não se resume ao estudo de cada um de seus elementos, mas consiste, sobretudo, em examinar as interações e as interferências que se estabelecem entre eles. É necessário entender as relações entre as espécies vegetais e animais pelos recursos naturais disponíveis, bem como as ligações de sinergia ou de complementaridade relativas à utilização dos recursos. Dessa forma, a distribuição e a repartição (no tempo e no espaço) da força de trabalho e dos meios de produção entre os diferentes subsistemas (de cultura e de criação) devem ser observados no decorrer do estudo (FIGUEREDO, 2009).

Silva Neto e Basso (2005) comentam ainda que os sistemas de produção correspondem à forma como os agricultores organizam as suas atividades no interior das UPAs. Ademais, devido à diversidade de situações sociais, ecológicas e a experiência específica acumulada pelos agricultores, duas UPAs não terão sistemas de produção idênticos. Não obstante, é possível agrupar sistemas de produção de um sistema agrário segundo certos condicionantes e problemas comuns, de forma a minimizar a diversidade existente entre os mesmos. A Figura 1 representa a abrangência e o encadeamento dos conceitos apresentados. 
Figura 1 - Representação da abrangência e encadeamento dos conceitos sistêmicos que permitem restituir, de maneira hierarquizada e lógica, a estrutura, a organização e as relações existentes em uma Unidade de Produção Agrícola.

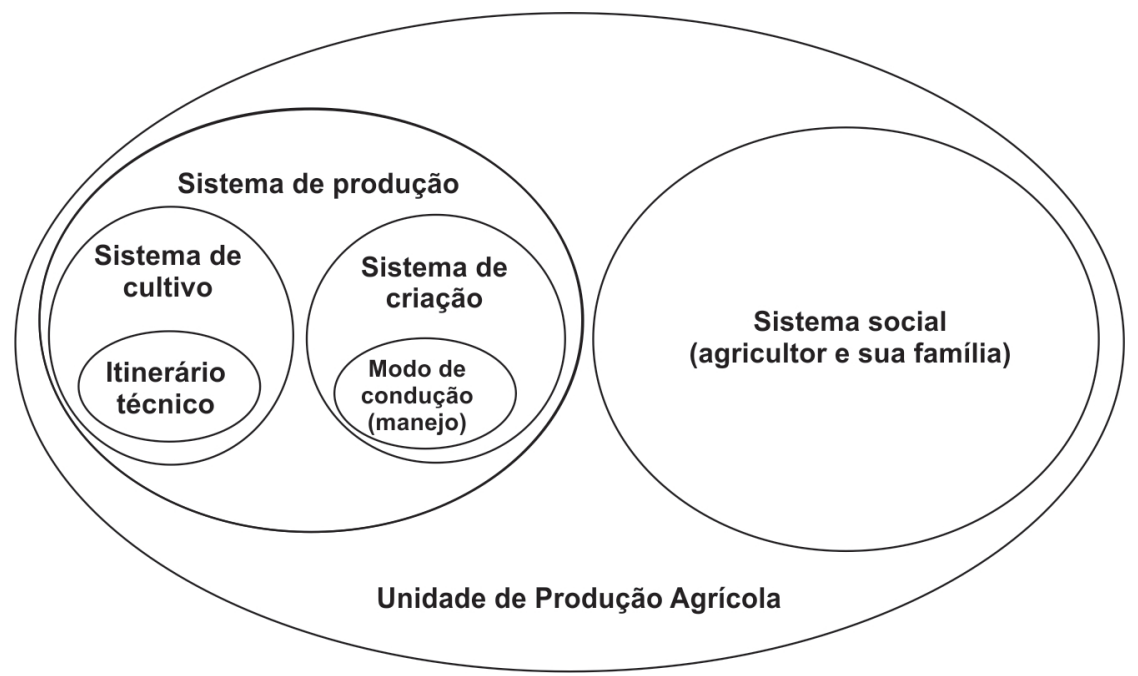

Fonte: Mazoyer e Miguel (2009).

Constata-se, a partir das fontes teóricas da Escola Francesa, a ausência de contribuições acerca do extrativismo. No entanto, com a adaptação do conceito de Sistema de Produção para áreas florestais, emergiu a necessidade de refletir sobre o extrativismo à luz desta abordagem teórico-metodológica. Assim, pesquisadores da Universidade Federal do Pará incluíram o Sistema Extrativista no Sistema de Produção. Contudo, o conceito de Sistema (subsistema) Extrativista não é encontrado na bibliografia. Segundo Oliveira ${ }^{1}$ (comunicação pessoal), esse subsistema contém elementos constituintes (caça, pesca, coleta de frutos, coleta de madeira etc.) aos quais são aplicados trabalho e capital (mesmo que pouco), e assume um papel no funcionamento do sistema de produção agrícola e na reprodução social da família, possuindo como característica inerente o fato de que se trata da exploração ou coleta de produtos que estão disponíveis na natureza, sem adotar processos de cultivos ou de criação.

A partir do exposto na Figura 1, evidencia-se que junto com os sistemas de cultivo e de criação há também o sistema extrativista. A ideia da existência de um sistema extrativista não é unânime. Observa-se que em estudos como o de Suarez, Coelho-de-Souza e Miguel (2008) sobre o extrativismo da samambaia-preta, a

\footnotetext{
1 Myriam Oliveira, professora da disciplina de Abordagem Sistêmica Aplicada aos Estabelecimentos Agrícolas Familiares, vinculada ao programa de Pós-Graduação de Agriculturas Amazônicas da UFPA. Troca de e-mails em abril de 2013.
} 
prática do extrativismo como uma atividade do sistema de produção vegetal vem à tona, buscando compreender se esta atividade pode ser considerada agrícola ou não. Os autores concluíram que em casos relacionados à samambaia-preta, o extrativismo pode ser considerado uma prática associada à produção vegetal.

Entretanto, segundo o conceito de Mazoyer e Miguel (2009, p. 18), em sentido amplo, a agricultura “[...] é uma atividade social de produção de bens obtidos pela exploração da fertilidade útil de um meio que contém geralmente populações de espécies domesticadas ou não [...]”. Partindo deste conceito, temse que o extrativismo também é uma atividade agrícola.

Contudo, antes de tentarmos aprofundar a reflexão sobre extrativismo no contexto do sistema de produção, faz-se necessária a revisão dos conceitos associados ao termo.

\section{OS CONCEITOS DE EXTRATIVISMO}

O debate acerca dos conceitos de extrativismo usualmente utilizados nas ciências agrárias, ambientais e sociais, exige, necessariamente, uma breve reflexão acerca de termos comumente associados, tais como coleta, apanha, catação e extração, dos quais o mesmo depende. Observa-se que em muitos casos esses termos são utilizados como sinônimos ${ }^{2}$, em alguns momentos como eufemismo, e em outros com significados distintos ${ }^{3}$. Homma (1993 [1980]) utiliza o termo "extrativismo de coleta" quando a atividade extrativa não leva à extinção da espécie. Por conseguinte, para este autor, coleta consiste num tipo de extrativismo que não leva à extinção da espécie. No caso do processo de licenciamento da samambaiapreta no Rio Grande do Sul, o termo utilizado foi coleta. Segundo Coelho-deSouza ${ }^{4}$, a utilização deste termo deveu-se ao fato de que, na perspectiva do órgão ambiental estadual, o termo extração tinha conotação pejorativa, em certos casos, por isso, utilizou-se o termo coleta ${ }^{5}$. Portanto, os dois casos ilustram como o termo coleta em alguns casos, pode representar um eufemismo para extração. Entretanto, ao que tudo indica, a utilização do termo coleta para questões relacionadas ao extrativismo advém do termo caçador-coletor.

2 Um exemplo de utilização dos termos coleta e extração como sinônimos está citado em Coelho-de-Souza et al. (2008).

3 Um exemplo de utilização dos termos coleta e extração não como sinônimos encontra-se na definição de Ferreira (1999).

4 Pesquisadora e professora professora do Departamento de Economia da Universidade Federal do Rio Grande do Sul. Desenvolve estudos sobre o extrativismo da samambaia-preta, comunicação pessoal, em setembro de 2010.

5 Na Lei da Mata Atlântica consta o termo coleta ao invés de extração. 
Por conseguinte, os termos apanha e catação são evitados, por serem considerados inadequados ao meio acadêmico. Os antropólogos, sociólogos e alguns etnoecólogos utilizam os termos conforme a comunidade estudada se identifica, como no caso das catadoras de mangaba (mulheres nordestinas) ou apanhadoras de mangaba (mulheres paraenses) (MOT'TA, 2010, em palestra).

Já o termo juntar é muito utilizado pelas comunidades, mas não se refere necessariamente à agricultura ${ }^{6}$, pois significa que estão recolhendo produtos caídos no chão, isto é, estão juntando frutos, sementes ou lenha. Além disso, a partir dos significados segundo o dicionário da língua portuguesa (HOUAISS, 2010), pode-se utilizar cada um desses termos conforme o produto, e onde está localizado.

Por exemplo, para a coleta de frutos, sementes, folhas, lianas e plantas inteiras podem ser utilizados os termos extração, coleta, apanha ou catação. Já para a casca, palmito, látex, goma ou raiz, normalmente se utiliza apenas o termo extração, pois subentende uma atividade que exige a utilização de ferramentas. Para a coleta de frutos e sementes caídos no chão, normalmente os termos mais utilizados são coletar, apanhar, catar ou juntar, dificilmente se usa o termo extração neste caso.

Com relação ao conceito de extrativismo, de forma semelhante ao conceito de biodiversidade, parece ser um conceito "pseudocognitivo" na medida em que todos assumem partilhar a mesma definição intuitiva (ARAÚJO, 1998). Esta observação foi referida por McIntosh (1985), "no contexto da utilização de conceitos básicos em Ecologia: 'ecologistas frequentemente utilizam uma palavra para significar o que eles querem que signifique não se preocupando se os outros darão o mesmo significado para ela"' (ARAÚJO, 1998, p. 2, tradução do autor). Portanto, um dos problemas nas análises e debates sobre extrativismo deve-ser ao uso do termo em vários sentidos, conforme o grupo profissional ou social.

Entre os poucos trabalhos teóricos no Brasil sobre o assunto, de Homma (1993). Define o extrativismo à luz da teoria econômica neoclássica.

[...] sempre foi entendido como primeira forma de exploração econômica, limitando-se à coleta de produtos existentes na natureza, com baixa produtividade ou produtividade declinante, decorrentes do custo de oportunidade do trabalho próximo de zero ou do alto preço unitário devido ao monopólio extrativo (HOMMA, 1993, p. 1).

Homma sustenta que a economia extrativa começa pela descoberta do recurso natural que apresenta possibilidade econômica ou utilidade, cuja

\footnotetext{
6 Agricultura, em sentido amplo, segundo o conceito de Mazoyer e Miguel (2009), referido anteriormente. Segundo este conceito, a agricultura também engloba o extrativismo.
}

Novos Cadernos NAEA •v. 17 n. 2 • p. 189-217 • dez. 2014 
sequência natural é o início do extrativismo como atividade econômica. Em geral, o crescimento do mercado e o processo tecnológico irão fazer com que seja iniciada a domesticação desses recursos extrativos ou que sejam descobertos substitutos sintéticos, como ocorreu com a borracha e o óleo de pau-rosa (HOMMA, 1993). Para o autor, toda atividade de cultivo, criação, manejo, beneficiamento ou processamento, mesmo integrando um sistema de produção e um modo de vida específico, não seria mais extrativismo, e sim domesticação.

Para Homma, há dois tipos de extrativismo - o extrativismo por aniquilamento ou depredação, e o extrativismo de coleta. $\mathrm{O}$ extrativismo por aniquilamento ocorre quando a obtenção do recurso implica na extinção da espécie. Já o extrativismo de coleta ocorre quando a atividade não leva extinção da espécie. Além disso, ambos os tipos de extrativismo também são diferenciados pela demanda do mercado, isto é, uma mesma espécie pode ser coletada quando a demanda é pequena e aniquilada quando a demanda é grande (HOMMA, 1993).

O conceito de extrativismo vegetal ${ }^{7}$ do Instituto Brasileiro de Geografia e Estatística (IBGE) vai ao encontro destas duas classificações criadas por Homma (1993). Para o IBGE, o extrativismo é a “[...] exploração dos recursos vegetais nativos através da coleta ou apanha de produtos, que permite a produção sustentada ao longo do tempo, ou de modo primitivo e itinerante, possibilitando, geralmente, apenas uma única produção" (IBGE, 2002, p. 49). Portanto, apesar do IBGE não diferenciar, como Homma, entre o extrativismo de coleta e o extrativismo por aniquilamento, identifica-se que há neste conceito a percepção destas duas formas de extrativismo. Em 1999, para tentar contrapor algumas ideias preconizadas por Homma e Rêgo (1999, p. 63), o IBGE criou o conceito de neoextrativismo, que está ligado

[...] à totalidade social, a todas as instâncias da vida social: econômica, a política e a cultural. Na dimensão econômica, é um novo tipo de extrativismo, que promove um salto de qualidade pela incorporação de progresso técnico e envolve novas alternativas de extração de recursos associadas com cultivo e beneficiamento da produção (IBGE, 1999).

Na interpretação de Clement (2006, p. 138), o conceito do "neoextrativismo reconhece os limites do extrativismo apresentado por Homma, e reconhece que o sistema de produção extrativo precisa se tornar modificado para se tornar economicamente, embora a implicação seja o fim do extrativismo (como foi definido por FERREIRA, 1999), via incorporação destas ideias, como afirmado por Homma”. Assim, o que volta à tona é o conceito de extrativismo, que até o

O IBGE distingue extrativismo vegetal, mineral e animal, o que os outros autores não fazem. 
momento está preocupado com a origem do produto, isto é, o seu não cultivo ${ }^{8}$.

Com a aprovação do Sistema Nacional de Unidades de Conservação da Natureza (SNUC), em julho de 2000, o conceito de extrativismo ganha a categoria de sustentável. Nos termos desta Lei, extrativismo é um “"...] sistema de exploração baseado na coleta e extração, de modo sustentável, de recursos naturais renováveis [...]" (SNUC, 2000, p. 8). Portanto, uma atividade extrativa só seria extrativismo se fosse sustentável, o que contrapõe a classificação proposta por Homma, na qual, dependendo do tipo de extração, pode ocorrer a extinção por se tratar da espécie.

Ao que tudo indica, no caso do SNUC há necessidade do termo sustentável, por se tratar de uma lei que visa "[...] definir, uniformizar e consolidar critérios para o estabelecimento e a gestão das áreas protegidas [...]" (SNUC, 2000, p. 5), destinados à conservação da natureza. $\mathrm{O}$ fato de considerar como extrativismo apenas as atividades de exploração que sejam sustentáveis, salvaguarda que as categorias de unidades de conservação de uso sustentável, mesmo liberando o extrativismo no seu plano de manejo, este só ocorrerá caso não leve as espécies à extinção. Por conseguinte, neste caso, o termo refere à conservação das espécies exploradas.

Em adição, para Lescure (2000, p. 191), o termo extrativismo origina-se na língua portuguesa, designando toda e qualquer exploração de recursos naturais. Para este autor, extrativismo refere-se a "[...] uma prática universal no espaço e no tempo: a exploração de recursos naturais com fins comerciais”. Em outro momento, Emperaire e Lescure (2000, p. 15) mencionam que "[...] o termo extrativismo designa os sistemas de exploração de produtos florestais destinados ao comércio regional, nacional ou internacional." O extrativismo diferenciar-se-ia, portanto, das atividades de coleta de produtos que estejam limitados ao consumo familiar ou a um escambo local. Assim, “[...] extrativismo e coleta dependem de duas lógicas econômicas diferentes, uma regulada por um mercado externo, outra pelas necessidades da unidade doméstica" (EMPERAIRE; LESCURE, 2000, p. 15). Esta ideia do termo extrativismo referir-se a uma atividade de cunho mercantil, já era mencionada por Clüsener-Godt e Sachs (1994). Além disso, o Dicionário Houaiss da Língua Portuguesa faz menção à finalidade da extração, considerando o extrativismo como a "Extração de produtos naturais para fins comerciais ou industriais." (HOUAISS, 2010, p. 345), demonstrando novamente que extrativismo é um termo que pode ser entendido de diversas formas.

Observa-se que para Clüsener-Godt e Sachs (1994) e Emperaire e Lescure (2000), o conceito está relacionado ao destino do produto extraído, e não necessariamente com a sua origem, como no caso dos quatro primeiros autores

\footnotetext{
8 Entende-se o cultivo como o plantio seguido de itinerário técnico.
}

Novos Cadernos NAEA •v. 17 n. 2 • p. 189-217 • dez. 2014 
(HOMMA, 1993; IBGE, 1999; RÊGO, 1999; FERREIRA, 1999) ou com a sustentabilidade da atividade, no caso do conceito do SNUC (2000).

Outra corrente de pesquisadores ligados ao Centro de Pesquisa Florestal Internacional (CIFOR) não utiliza o termo extrativismo, e sim Produtos Florestais não Madeireiros (PFNM). Isto se torna evidente na cartilha Manejo de Produtos Florestais não Madeireiros, na qual o autor menciona que, naquele contexto, o manejo de Produtos Florestais não Madeireiros também era conhecido como neoextrativismo ou extrativismo sustentável (MACHADO, 2008, p. 11). O que se observa várias em publicações é a utilização do termo PFNM (NEUMANN; HIRSCH, 2001; KUSTER; BELCHER, 2004; BELCHER et al., 2005; QUANG; ANH, 2006; MACHADO, 2008), ao que tudo indica, a opção pela não utilização do termo extrativismo ocorre porque o foco está no produto e não no sistema de produção, ou no destino do mesmo, não havendo, assim, a necessidade de ser um produto oriundo de uma população natural, ser sustentável ou ser comercializado (pressupostos que apareciam nos conceitos supracitados).

Mais recentemente, outros autores (BENJAMIN, 2004; GUERRA, 2011) e também algumas instituições (PRÓ-JOVEM, 2008; MMA, 2012) estão utilizando o termo agroextrativista, que consiste na “[...] combinação de práticas agrícolas - culturas anuais e culturas permanentes - e extrativistas." (BENJAMIN, 2004, p. 1). Possivelmente, a adoção deste novo termo indica o reconhecimento de que o extrativismo é uma prática associada a outras atividades agrícolas e não agrícolas. Um estudo realizado por Pizón Rueda (s.d.) em Reservas Extrativistas, identificou que as famílias conseguem $55 \%$ de sua renda familiar da agricultura e da criação, 14\% do extrativismo animal e 30\% da extração vegetal. $\mathrm{Na}$ interpretação de Clement (2006, p. 5), “[...] os extrativistas mais conhecidos são agricultores familiares que praticam extrativismo". Ainda segundo o autor "[...] a maioria dos agricultores familiares do Brasil segue um padrão, algo similar, embora a extração vegetal e animal certamente seja menos importante e a agricultura mais importante em outros lugares do que nas Reservas Extrativistas" (CLEMENT, 2006, p. 5).

Por fim, cabe ressaltar que a extração de produtos da floresta é algo muito mais antigo do que a agricultura propriamente dita, e faz parte do sistema de produção 9 de muitos agricultores nos diversos biomas, principalmente nas regiões tropicais e subtropicais. Portanto, o extrativismo deve ser pensado e entendido não apenas se referindo a uma 'fotografia', isto é, a um momento apenas, mas sim de maneira sistêmica, englobando toda a unidade de produção ao longo do tempo.

Entendido como a combinação entre subsistemas dentro da Unidade de Produção Agrícola (UPA), podendo se restringir apenas ao limite da UPA ou não. 


\section{EXTRATIVISMO VEGETAL E SISTEMA DE PRODUÇÃO}

A partir da unidade de produção agrícola, o sistema de produção pode ser definido como uma combinação, no tempo e no espaço, dos recursos disponíveis, com a finalidade de obter produtos vegetais e animais. Pode também ser entendido como uma combinação coerente de vários subsistemas produtivos (DUFUMIER, 2007).

Dufumier (1996) ressalta que é de fundamental importância identificar a coerência e a complexidade interna dos sistemas de produção, bem como as relações de sinergia ou de complementaridade relacionadas à utilização dos recursos, evidenciando a complexidade das estruturas desenvolvidas, que mudam em função de um conjunto de variáveis, desde o objetivo dos produtores até os fatores climáticos, sociais, econômicos, culturais e políticos na construção dos sistemas de produção agropecuária. Para este autor, estes sistemas emergem da organização de recursos no tempo e no espaço, para que os agricultores alcancem os seus objetivos.

De acordo com Villaret (1994), um sistema de produção não pode ser compreendido como uma estrutura estática no tempo. Pelo contrário, é uma estrutura dinâmica, em constante mudança. Como salienta Deffontaines (1973), mesmo que muitos estudos demonstrem o tempo e o espaço como sendo variáveis relevantes para o entendimento dos sistemas, ainda (em muitos casos) consideram as explorações rurais como unidades estáticas, e não como um espaço de produção organizado ao longo do tempo e arraigado num espaço de relações (WIVES, 2008).

Estudos desenvolvidos sob o enfoque de Sistema de Produção tiveram início no Brasil na década de 1980. Contudo nesta perspectiva, quase não há estudos englobando atividades extrativistas - ou acerca da inserção e articulação do extrativismo dentro do sistema de produção. Uma das poucas tentativas de estudar o extrativismo a partir desta ótica é realizada na Universidade Federal do Pará, no curso de Agronomia, no qual é adotada a abordagem sistêmica como estruturante. Segundo Michelotti ${ }^{10}$, várias disciplinas abordam as questões mais específicas de uma unidade de produção agropecuária (produção vegetal, produção animal, horticultura etc.), mas há aquelas disciplinas que se utilizam das ferramentas de análise do sistema família-estabelecimento agrícola para tentar integrar questões mais específicas e explicar a dinâmica do seu estabelecimento como um todo. Assim, centra-se no conceito de Sistema de Cultivo, que busca

10 Comunicação pessoal do Prof. Fernando Michelotti, coordenador do curso da UFPA, via emails trocados em abril de 2010.

Novos Cadernos NAEA • v. 17 n. $2 \cdot$ p. 189-217 • dez. 2014 
integrar as várias questões disciplinares ligadas à produção vegetal; no conceito de Sistema de Criação, que busca integrar a produção animal; e no conceito de Sistema Extrativista, que busca interligar elementos do extrativismo de produtos florestais madeireiros e não madeireiros com o funcionamento global da unidade de produção.

No entanto, uma questão de fundo permanece recorrente e sem resposta: Como o extrativismo está inserido no sistema de produção? O extrativismo seria realmente um sistema à parte? Ou ele estaria inserido no sistema de cultivo?

Levando-se em consideração a temporalidade, como salientado por Villaret (1994) e Deffontaines (1973), buscou-se um diálogo com autores que se utilizam da Ecologia Histórica e as abordagens de domesticação ${ }^{11}$ e etnoecologia para tentar compreender a dinâmica do extrativismo no sistema de produção. A busca do diálogo com essas abordagens ocorre pela premência em demonstrar que paisagens tidas como "naturais" são, na realidade, produtos da ação humana durante um determinado período (HECKENBERGER et al., 2003; CLEMENT; JUNQUEIRA, 2010; REIS; LADIO, 2012). Assim, estudos sobre sistemas de produção, em especial sobre extrativismo, não podem negligenciar a temporalidade e as relações entre agricultores/coletores e a paisagem. Visando demonstrar a importância destes aspectos, serão explicitados a seguir três estudos de caso sobre o extrativismo vegetal, e posteriormente serão realizados alguns apontamentos em relação ao extrativismo animal.

No caso do extrativismo da samambaia-preta, a sua coleta está associada principalmente aos estádios sucessionais iniciais de regeneração da Mata Atlântica, isto é, áreas que sofreram intervenção pelo desmatamento e queima ("agricultura de queimada"), e estão em processo de regeneração. Desta forma, os principais locais de extrativismo desta espécie, identificados pelos samambaieros ${ }^{12}$, são as antigas áreas de cultivo (COELHO-DE-SOUZA, 2003; BALDAUF; HANAZAKI; REIS, 2007; SUAREZ; MIGUEL; COELHO-DE-SOUZA, 2008).

Apesar da samambaia-preta ser considerada ecologicamente como uma espécie pioneira, muitos extrativistas afirmaram não realizar nenhuma intervenção na paisagem para manter as áreas produtivas, simplesmente procurando outros

11 A Ecologia Histórica pode ser considerada como um novo programa de pesquisa interdisciplinar, focada na compreensão das dimensões espaciais e temporais do relacionamento de populações humanas com ambientes locais e na compreensão dos efeitos cumulativos deste relacionamento (BALÉE, 2006). Este enfoque complementa a abordagem de domesticação, como a de domesticação de paisagem de Clement (1999). No contexto da Ecologia Histórica, a paisagem é uma inscrição histórica, cultural e evolutiva da relação homem-ambiente ocorrida em determinado local. Dessa forma, uma análise criteriosa da paisagem pode revelar a infraestrutura, como por exemplo, a composição de espécies muitas vezes usadas como recursos, e as estratégias de manejo que existem e/ou existiram numa determinada localidade (BALÉE, 2006).

12 Pessoas que praticam o extrativismo da samambaia-preta. 
locais para exploração "quando a capoeira engrossa". Ao serem questionados sobre esta estratégia, relataram dois motivos principais: a legislação ambiental ("o Ibama") e o fato de não valer a pena, do ponto de vista econômico, gastar tanto tempo com esta atividade. Alguns afirmaram realizar pequenas intervenções, como podas e roçados na vegetação, para aumentar a incidência de luz nas áreas de coleta de samambaia-preta (COELHO-DE-SOUZA, 2003; BALDAUF; HANAZAKI; REIS, 2007; SUAREZ; MIGUEL; COELHO-DE-SOUZA, 2008).

Uma associação evidenciada por Suarez, Miguel e Coelho-de-Souza (2008) e por Baldauf, Hanazaki e Reis (2007) é a extração de samambaia em áreas de pousio agrícola.

Neste sistema, de maneira geral, as áreas em estádios sucessionais médios ou avançados (capoeirão) são desmatadas e queimadas no período do inverno e em seguida são implementados cultivos anuais (geralmente milho e feijão). Após a realização das colheitas, as áreas são deixadas em pousio. Conforme os entrevistados, após um ano de abandono das áreas cultivadas, as malhas ${ }^{13}$ de samambaia começam a aparecer. Todavia, estes não consideram recomendável a coleta no primeiro ano, visto que neste período a samambaia estaria fraca e com frondes pequenas. De acordo com a maioria dos extrativistas, somente a partir do segundo ano de pousio que se torna possível começar a coletar as frondes sem prejudicar a planta. Nestes casos, o manejo da paisagem é bastante intenso, pois se baseia no sistema tradicional de derrubada e posterior queima da vegetação da capoeira, mantido historicamente pelos agricultores da região. Conforme relatado pelos entrevistados, esta associação entre sistemas de cultivo de plantas anuais e extrativismo de samambaia já foi bem mais freqüente na região, diminuindo consideravelmente devido às restrições impostas pela legislação ambiental ${ }^{14}$ (BALDAUF; HANAZAKI; REIS, 2007, p. 829).

Outra estratégia encontrada por estes autores na região foi a extração da samambaia em áreas onde a capoeira foi substituída por pastagem para bovinos. Segundo os autores, estas áreas são periodicamente queimadas, e as "bolas"15" de samambaia aparecem durante a regeneração da vegetação.

Além do manejo das áreas de capoeira, onde são realizadas as coletas das frondes, também foi constatada pelos mesmos autores a existência de práticas que visam assegurar ou intensificar a brotação de novas frondes, bem como garantir uma boa produtividade das áreas: "Estas práticas são aqui denominadas de 'práticas de manejo de populações de samambaia', sendo que as duas

13 Áreas com alta densidade de samambaia.

14 Decreto Federal n ${ }^{\circ} 750$, de 10 de fevereiro de 1993, o qual pró́be o corte, a exploração e supressão de vegetação primária ou nos estádios avançado e médio de regeneração da Mata Atlântica.

15 Áreas com alta densidade de samambaia.

Novos Cadernos NAEA • v. 17 n. 2 • p. 189-217 • dez. 2014 
principais técnicas são o pisoteio das 'bolas' de samambaia e a retirada de frondes senescentes após a coleta" (BALDAUF; HANAZAKI; REIS, 2007, p. 829).

Com base neste estudo de caso, pode-se observar que o extrativismo da samambaia-preta, em muitos casos, está inserido em um sistema de cultivo e associado ao sistema de criação praticado no âmbito das unidades de produção agrícola.

Outro caso de extrativismo cuja inserção em um sistema de cultivo é evidente é o da erva-mate (Ilex paraguaiense) (MATTOS, 2011, REIS et al. 2013) ou o caso da bracatinga (Mimosa scrabella), em que se observa uma domesticação da paisagem (STEENBOCK, 2009). Entretanto, há casos em que o extrativismo aparece inserido em um sistema de cultivo, mas de maneira não tão evidente como o extrativismo da castanha-do-pará (Bertholetia excelsa) e do açaí (Euterpe oleracea) na Amazônia, do palmito juçara (Euterpe edulis) na Floreta Ombrófila Densa (uma das fitofisionomias da Mata Atlântica), da araucária (Araucaria angustifolia) na Floresta Ombrófila Mista, entre outros.

No caso da castanha-do-pará, estudos em etnobiologia iniciados na década de 1980 por Balée (1989) e Anderson e Posey (1989) sobre diversos grupos indígenas, mostram que a castanheira não é uma espécie cujas sementes são simplesmente coletadas na floresta, mas é objeto de diferentes práticas de manejo, tais como proteção, multiplicação e eventual seleção (EMPERAIRE; MITJA, 2000).

Para Clement (1990), a castanheira é uma espécie manejada. Elas são protegidas e/ou multiplicadas pelo homem, sem que haja transformação do seu ecossistema. Pela definição de Leakey e Newton (1994) este manejo não implica a priori uma seleção, embora possa favorecê-la, pois há a tendência à reprodução dos indivíduos mais interessantes. A partir das informações de B. Nelson sobre a existência de uma população da espécie com sementes de tamanho importante na região situada entre os rios Juruá e Purus, Clement (1990) formula a hipótese de uma seleção indígena da castanheira.

Segundo Emperaire e Mitja (2000), independente desta eventual seleção, outros índices convergem para demonstrar que ocorre um verdadeiro manejo da castanheira. Portanto, a partir desses estudos, pode-se conceber que a castanheira está inserida em um sistema de cultivo necessariamente mais abrangente e englobante que o próprio ato de extração. Trabalhos realizados a partir da década de 1980, sobre os sistemas de cultivo indígenas e sobre a ecologia da castanheira, confirmam esta afirmação.

Há indícios de que os índios Kaiapó, no Pará, segundo Anderson e Posey (1989), plantavam as castanheiras em florestas, em capoeiras ou em clareiras 
naturais. Segundo Posey (1993), essa árvore, além de ter sua utilidade direta (sementes, madeiras e cascas), também era um marcador de território. Outro fato interessante ao qual Balée (1989) chama a atenção é a presença de florestas dominadas por castanheiras nas proximidades de terras pretas antropogênicas e de sítios arqueológicos. Esse mesmo autor, e posteriormente Clement e Villachica (1994), chegam a considerar a vasta distribuição da castanha-do-pará como de origem antrópica. Associações com vestígios de presença humana, densidades que às vezes atingem 10 indivíduos/hectare (CLEMENTE; VILLACHICA, 1994), o caráter heliófilo da espécie, que favorece o seu crescimento em lugares abertos, são evidências disso, segundo Emperaire e Mitja (2000).

Contudo, as mesmas autoras indicam outros trabalhos que evidenciam a ocorrência de regeneração natural importante nas clareiras, sem intervenção humana (KAHN, 1983; EMPERAIRE, 1995 apud EMPERAIRE, 2000). Mesmo nestes casos, muitas vezes a abertura de clareiras para o cultivo de roças não deixa de ser uma forma de favorecer a regeneração da espécie, não contradizendo a influência antrópica no desenvolvimento da espécie em questão. Afinal, segundo as autoras, a "associação da castanheira com a agricultura de corte e queima é uma prática indígena encontrada em diversas regiões da Amazônia" (EMPERAIRE; MITJA, 2000, p. 114). Outra prática muito comum na Amazônia é a proteção da castanheira com um anel de vegetação ao redor de seu fuste, com a finalidade de protegê-la do fogo.

Pereira (2000), num estudo realizado em 1991, demonstrou que a localização das novas roças é escolhida pelos Kokamas de modo a evitar a proximidade das castanheiras.

O posicionamento das roças é cuidadosamente definido, permitindo que essas árvores permaneçam protegidas em faixas de floresta que separam as parcelas de cultivo que nunca se justapõem diretamente. Em geral, o tamanho relativamente pequeno das roças, sempre menores que 2 hectares, permite esse arranjo espacial. Se o arranjo torna-se impossível, medidas de proteção aos espécimes florestais de interesse econômico são tomadas: as árvores não valorizadas são abatidas de maneira que suas copas tombem o mais distante possível das castanheiras; o fuste dos indivíduos de castanheira é protegido do fogo intenso por um anel de vegetação conservado em pé em torno de seus troncos. (p. 70).

Ainda segundo este autor, vários índices comprovam uma gestão antiga das castanheiras dessa região, anterior à chegada dos Kokamas. O autor cita dois inventários que foram realizados - um em floresta primária e outro nas faixas de roças-e-capoeiras. Os dados destes inventários indicam 1,8 contra 3,1 indivíduos por hectare, respectivamente. Assim, essas afirmações, corroboradas 
por outros estudos, podem indicar que a prática da agricultura de corte-e-queima com longos períodos de pousio possa ter estimulado a regeneração da espécie, causando, inclusive, um possível adensamento.

Neste estudo de caso, a relação da castanheira com o sistema de produção é mais sutil e mais distante ao longo do tempo, o que pode dificultar a análise. Todavia, o que se observa é um favorecimento da espécie na paisagem, visto que as árvores são protegidas, e em algumas localidades há indícios de plantios e adensamentos antigos, realizados por grupos indígenas que habitavam a região. De qualquer forma, este estudo de caso contesta novamente o caráter de paisagem prístina associado ao extrativismo.

Estudos com a araucária nos permitem conceber para esta espécie hipóteses semelhantes às da castanheira. Bitencourt e Krauspenhar (2006), cruzando dados arqueológicos, geográficos, palinológicos e botânicos, apresentam reflexões sobre a influência antropogênica pré-histórica na expansão da araucária durante o Holoceno tardio. Segundo as autoras, estudos arqueológicos revelaram que grupos de caçadores e coletores, pertencentes ao tronco cultural Jê, definidos arqueologicamente como Tradição Taquara/Itararé, ocuparam a região do planalto sul brasileiro, onde a caça, a coleta de pinhão e o manejo agroflorestal constituíam os principais recursos relacionados à floresta.

Cabe salientar que para os Kaingang, um dos grupos do tronco cultural $J \hat{e}$, os limites entre os territórios das aldeias eram sinalizados através de marcas nas cascas dos pinheiros (MABILDE, 1983). Embora estes territórios tivessem regras comunais, que permitiam a circulação de todos por diferentes aldeias, a única exceção era para o pinhão, considerado um recurso de usufruto exclusivo da aldeia que habitava um determinado território. Pode-se inferir que uma das razões para esta atitude relacionava-se ao fato de que além do pinhão ser um recurso alimentar importante, principalmente no inverno, ele também atraía a fauna, acarretando maior quantidade de animais para a caça. Inferência semelhante é feita por Schmitz (2011).

Além disso, os seus assentamentos em casas subterrâneas estão distribuídos altimétrica e geograficamente sob o domínio da Floresta Ombrófila Mista.

A expansão de Araucaria angustifolia no Holoceno tardio é fortemente assinalada em vários trabalhos palinológicos, depois de 1500 anos A.P. no Paraná, 1000 anos A.P. em Santa Catarina e 1140 anos A.P. no Rio Grande do Sul, em áreas próximas aos assentamentos arqueológicos. Esses dados chamam a atenção. Além disso, fontes botânicas indicam que Araucaria angustifolia necessita de um agente dispersor, citando aves, animais e o próprio homem. Apesar das condições climáticas serem apontadas como a principal causa desse aumento, discute-se, também, a possibilidade 
de uma contribuição da ação dos grupos de caçadores-coletores com cerâmica da Tradição Taquara/Itararé na dispersão da espécie, pela coleta do pinhão, manejo e o possível plantio da espécie. Estes sítios constituem, ainda, elementos importantes em estudos de reconstituição da paisagem como indicadores de áreas de floresta com araucária (BITENCOURT; KRAUSPENHAR, 2006, p. 1).

Klein (1960) revela que as diferentes comunidades de Araucaria angustifolia são antes fases sucessionais do que comunidades maduras e integradas, o que é confirmado por Soares (1979). Ainda segundo Klein (1978), o pinheiro é uma espécie pioneira, uma vez que coloniza áreas abertas, e não se regenera quando a sombra se torna intensa. No entanto, a araucária apresenta algumas características fundamentais que a diferem das pioneiras: suas sementes são grandes, pesadas e ainda perdem rapidamente o poder germinativo; espécies pioneiras são também capazes de suportar ambientes inóspitos, pelo menos nas regiões de ocorrência, todavia, plantas jovens de araucária não resistem a geadas severas em seu próprio habitat, quando não existe proteção de árvores maiores (SOARES, 1979).

Soares (1979) classifica a A. angustifolia como sendo uma espécie 'série', tendo como base o trabalho de Maack (1968). Este último autor observou que os melhores resultados de crescimento de araucária foram obtidos quando a espécie estava sob as copas de vegetação secundária. Isso demonstra que nos primeiros anos de vida, a araucária é uma espécie tolerante à sombra, como também observou Dillemburg et al. (2009), ao contrário das pioneiras, que são intolerantes durante todo o seu ciclo de vida.

Desta maneira, Soares (1979) parte da premissa de que a araucária é uma espécie 'série', e que para se regenerar nas áreas de florestas, necessitaria de algum distúrbio que ocasionasse a abertura de uma clareira. Caso contrário, ela seria dominada pelas latifoliadas durante a sucessão vegetal. A necessidade de clareiras para um maior recrutamento de araucária é evidenciada por Puschalsky et al. (2006) e, segundo Reitz e Klein (1966) e Dillemburg et al. (2009), a regeneração da araucária ocorre em ambientes abertos como as pastagens e clareiras nas florestas.

No passado, ainda segundo Soares (1979), esses distúrbios foram causados por raios ou por queimadas indígenas, o que permitiu ao pinheiro ocupar diversas áreas. Em sua explanação, o autor argumenta que a araucária é uma espécie dependente do fogo, por apresentar alta flamabilidade e características de resistência ao fogo (casca espessa, copa alta, praticamente livre do risco de crestamento das acículas pelo calor do fogo). A resistência da araucária ao fogo foi relatada também por Reitz e Klein (1996) e por Mattos (1994). Um dado que 
corrobora as hipóteses levantadas por estes autores é um trecho da palestra de Hermann Behling ${ }^{16}$, ao afirmar que o fogo era quase ausente no Pleistoceno e se tornou frequente no Holoceno médio. Ademais, estudo recente (BEHLING; PILAR, 2007) indica que o fogo era frequente durante o período de expansão da araucária.

Portanto, esses estudos reforçam a importância que o sistema de cultivo indígena teve para a manutenção das populações de araucária. Reis e Ladio (2012) afirma que as florestas de araucária da América do Sul ${ }^{17}$ são paisagens culturais. $\mathrm{E}$ isso se deve também à importância que o pinhão tinha na alimentação desses grupos indígenas, como ressalta Santos (1968), Mabilde (1983) e Vieira (2004).

Para Reis e Ladio (2012, p. 14), evidências apóiam, ou pelo menos não contradizem que as culturas que interagiram com as florestas de araucária favoreceram a regeneração da espécie, e que estas comunidades possivelmente reconheceram as características ecológicas da araucária, podendo, manejá-la e/ ou manipular suas áreas conforme os seus critérios culturais e simbólicos. Assim, essas florestas foram utilizadas de acordo com normas culturais que regraram o uso racional e sustentável da espécie (REIS; LADIO, 2012, p. 14).

A partir disso, uma questão se impõe: Será a existência da variedade pinheiro-macaco, de pinha indeiscente, decorrente de procedimentos de um processo de domesticação realizado pelos indígenas?

Estes três casos relatados demonstram que ao analisar o extrativismo vegetal a partir de um sistema mais amplo, levando-se em consideração a temporalidade deste sistema, como salienta Villaret (1994) e Deffontaines (1973), este pode estar inserido ou em intersecção com o sistema de cultivo, podendo ser mais ou menos evidente, como demonstraram os casos relatados.

Entretanto, cabe ressaltar que há casos como o extrativismo de macrófitas aquáticas, em que não existe uma relação direta evidente com o sistema de cultivo implementado por agricultores e coletores. Estudos revelam que algumas espécies de macrófitas como o junco (Schoenoplectus californicus C.A. Meyer) e a taboa (Typha domingensis Pers.) são utilizadas na confecção de artesanato, como ilustram os estudos da ANAMA/PGDR-UFRGS (2003) e de Coelho-de-Souza (2003) para a região do litoral norte do Rio Grande do Sul. Nesta região, a extração destas espécies configura-se como uma importante fonte de renda para algumas famílias de agricultores, pescadores artesanais, coletores e artesãos.

\footnotetext{
16 Universität Göttingen, Albrecht von Haller Institute for Plant Sciences, Department of Palynology and Climate Dynamics. Palestra ministrada no $56^{\circ}$ Congresso Nacional de Botânica, em Curitiba, 2005.

17 Araucaria angustifolia, no Brasil e Araucaria araucana, na Argentina e no Chile.
} 
A utilização destas espécies como fonte de renda, e a consequente utilização das macrófitas por um longo período de tempo, fazem com que os coletores adquiram um conhecimento empírico. Deste conhecimento derivam as intervenções e práticas associadas ao manejo destas espécies. Cabe salientar que estas práticas em populações de macrófitas aquáticas são reduzidas e limitadas ao corte seletivo da vegetação em épocas determinadas e com intensidade controlada. Tem-se, assim, uma aproximação por parte dos coletores do conhecimento associado e a preocupação com o estoque e regeneração da espécie. Portanto, pode-se afirmar que o extrativismo das macrófitas configura-se como um sistema de cultivo, sem apresentar uma articulação com outras práticas agrícolas ou mesmo do manejo de outras espécies. Assim, o extrativismo das macrófitas, conforme relatado acima, pode ser considerado como um sistema de cultivo.

\section{E O EXTRATIVISMO ANIMAL?}

Primeiramente, deve-se ressaltar que não se pretende aqui esgotar este assunto, visto que este estudo tem como foco o extrativismo vegetal e não o animal. Entretanto, diante de algumas evidências encontradas na literatura cabe levantar alguns pontos, com o intuito de contribuir para o debate sobre o sistema extrativista dentro do sistema de produção.

Em relação ao extrativismo animal, observa-se que em algumas comunidades também ocorre um cuidado com as espécies de interesse. Segundo Reichel-dolmatoff (1978, p. 286 apud POSEY, 1997), os xamãs Desâna inventariam, periódica e continuamente, os recursos naturais utilizados, dentre eles a caça, com vistas a orientar as atividades de subsistência do grupo. Esses inventários contínuos denotam a preocupação dos índios em bem administrar os recursos naturais disponíveis.

Outro fato interessante é que pequenos mamíferos, como a cutia (Dasyprocta $s p$ ) e a capivara (Hydrocherus hudrochaeris), ou aves como o mutum (Crax sp), podem ser mantidos em estado de semidomesticação nas áreas de capoeira em sítios fechados com cercas ou nas proximidades de hortas domésticas, produzindo um excedente substancial (POSEY, 1997). A atração dos animais de caça para junto das plantações também é observado a partir dos relatos de Silva Junior (2012), em que a comunidade por ele estudada ${ }^{18}$ afirma "que o ambiente criado a partir do preparo da área para o roçado seria inclusive apreciado pelos animais [...] 'é mais um lugar onde tem o que comer para eles né?”' (SILVA JUNIOR, 2012, p. 51). Ademais, Posey (1997, p. 11) afirma que

18 Reserva Extrativista Arióca Pruanã, em Oeiras do Pará.

Novos Cadernos NAEA • v. 17 n. 2 • p. 189-217 • dez. 2014 
Conscientes da importância das antigas roças para atrair a fauna, os Kaypó abrem campos de cultivo a grande distância das aldeias, maximizando as potencialidades de manipulação das mesmas. Essas estratégias de manejo em larga escala produzem reservas florestais densas, artificialmente construídas, que minoram o esforço das caçadas e melhoram os resultados.

Estudo realizado por Barros (2011) na Reserva Extrativista (RESEX) Riozinho do Anfrísio, evidencia que o acúmulo de conhecimentos adquiridos sobre o mutum (Pauxi tuberosa), e certos cuidados com a espécie, indicam que a caça desta espécie pode ser considerada uma prática sustentável.

Em relação à pesca, estudos realizados junto aos Kayapó revelaram que o grupo não só conhece os padrões de migração e de cruzamento dos peixes, como detêm um extenso inventário das espécies (PETRERE, 1990). Barros (2011, p. 159-161) relata que os ribeirinhos da Resex Riozinho do Anfrísio, além do vasto conhecimento sobre ictiofauna local, cada pescador possui pontos de pesca que são mantidos em segredo.

O ponto de pesca é uma área especial descoberta pelo pescador onde uma espécie específica de peixe pode ser encontrada com maior frequência. Tais áreas recebem um manejo especial. No final do inverno, o pescador remove a vegetação ao redor do ponto de pesca para facilitar a pesca no verão. Estas áreas são identificadas por alguma característica natural específica do lugar, como pedra, árvore, etc. Os pontos de pesca são usados tanto para a pesca de autoconsumo como para a pesca comercial, mas somente quando a atividade não envolve membros de fora do núcleo familiar (BARROS, 2011, p. 159, tradução da autora).

Ainda segundo o autor, esses ribeirinhos possuem diversos elementos culturais, como as lendas e mitos que moldam a relação entre os pescadores e a natureza (BARROS, 2011).

Outro exemplo relacionado à pesca é o manejo sustentável do pirarucu na Reserva de Desenvolvimento Sustentável Mamirauá (AM), onde o método de contagem utilizado pelos pescadores artesanais se mostrou mais eficiente do que o método científico tradicional de captura e marcação nos lagos de várzea (CASTELLO, 2004). Dessa forma, atualmente, o método de contagem é instrumento fundamental exigido pelo IBAMA para o manejo sustentável da espécie. Assim, adota-se o resultado da contagem de pirarucus adultos do ano anterior como base para solicitar a cota do ano corrente (AMARAL et al., 2011).

Assim como os peixes, a carne de tartaruga é muito apreciada na alimentação humana. Desde a época pré-colombiana, os índios amazônicos construíam currais para a criação de tartarugas, consumindo seus ovos e carne durante todo o ano (SMITH, 1974, p. 85 apud POSEY, 1997). 
Com base nesses relatos, observa-se que a utilização destas espécies como fontes de alimento e renda, e por um longo período, faz com que os caçadores adquiram um conhecimento empírico. A partir deste conhecimento, derivam alguns regramentos e práticas associadas ao manejo dessas espécies. Embora as práticas em relação às populações animais sejam limitadas basicamente os inventários e ao manejo de áreas florestais para a atração de determinadas espécies, há uma preocupação com o estoque desses recursos. Portanto, evidencia-se que em alguns casos o extrativismo animal pode também se configurar como um sistema de criação.

\section{TENTANDO CONTRIBUIR...}

Ocorre uma tendência a interpretar a agricultura como sendo um amálgama de espécies domesticadas conduzidas racionalmente a partir das práticas de cultivo. No entanto, esta seria uma visão bastante reduzida da diversidade encontrada, e passível de constatação empírica em nível dos sistemas de produção existentes. Os estudos e resultados de pesquisas apresentados neste artigo procuram demonstrar a necessidade de uma análise sistêmica do extrativismo e uma revisão sobre a sua inserção no sistema de produção.

Evidenciam, portanto, que as formas de extrativismo vegetal e animal exigem conhecimentos associados e diversos graus de intencionalidades relacionados à manutenção e promoção do estoque de determinadas espécies. Dessa maneira, deve-se pensar o sistema de cultivo e o sistema de criação como possuidores de graus distintos, em um gradiente que vai desde o cultivo e criação de espécies domesticadas, aliados às práticas agrícolas convencionais, até o extrativismo vegetal e animal, com práticas de manutenção e promoção de determinadas espécies. Assim, o extrativismo vegetal está inserido no sistema de cultivo, bem como o extrativismo animal está inserido no sistema de criação dos diversos sistemas de produção praticados por grupos sociais distintos. Portanto, os diversos sistemas de produção respondem às demandas sociais e ecológicas de maneira eficiente.

Cabe ressaltar que para analisar o extrativismo a partir da Teoria de Sistemas Agrários, a Ecologia Histórica, a abordagem das domesticações e a etnoecologia são ferramentas relevantes, pois contribuem para o entendimento, ao longo do tempo, das relações do extrativismo dentro do sistema de produção.

Como fruto desta reflexão, pretende-se apresentar a definição de uma proposta de conceito para o extrativismo. $\mathrm{O}$ conceito proposto permite uma 
real e efetiva integração aos demais conceitos existentes no âmbito da descrição e caracterização de uma unidade de produção agrícola, a partir da abordagem sistêmica. Assim:

Extrativismo: é um sistema complexo e dinâmico, consiste em uma atividade que ocorre na paisagem, independente do seu estágio de domesticação (ver graus de domesticação de paisagem em CLEMENT, 1999), e consequentemente modificará esta paisagem, possivelmente aumentando o seu grau de domesticação. No entanto, a espécie explorada não deve ser totalmente domesticada ${ }^{19}$ (ver graus de domesticação de espécie em CLEMENT, 1999). Ressalta-se que a exploração contínua de determinadas espécies pode gerar um acúmulo de conhecimentos acerca da mesma, fazendo com que extrativistas tenham práticas específicas de manejo para cada espécie extraída. ${ }^{20}$

A partir das reflexões realizadas neste artigo, observa-se a premência em expandir o conceito de Dufumier ${ }^{21}$, incluindo no sistema de produção as áreas de uso ocasional como florestas, rios e lagos, de onde se extrai PFNM, caça e pesca, podendo ocorrer, desta maneira, sistemas de produção difusos, isto é, que não estão delimitados por uma propriedade rural.

Neste sentido, cabe salientar que o indicador de Superfície Agrícola Útil deve ser repensado, com o intuito de englobar as áreas de florestas, principalmente nos casos em que o extrativismo tem grande importância, seja em termos de dedicação à atividade, seja em relação à renda gerada.

\section{CONSIDERAÇÕES FINAIS}

A partir da revisão aqui apresentada, pode-se observar que os conceitos usualmente utilizados para definir o Sistema de Produção Agrícola ao nível das Unidades de Produção Agrícola apresentam limitações e restrições, pois não incorporam, na sua essência, as atividades de extrativismo.

Constatou-se, assim, a necessidade de expandir o conceito de sistema de produção elaborado por Dufumier $(1996,2007)$, incluindo no sistema de produção

19 Espécie cujas características de adaptabilidade ecológica foram alteradas a tal ponto onde elas conseguem sobreviver apenas em ambientes criados pelo homem, principalmente paisagens cultivadas. E, portanto, se a intervenção humana na paisagem cessar, a espécie pode morrer em um curto período de tempo (CLEMENT, 1999, p. 3).

20 Contrapondo a definição de Lescure e Emparaire (2000), nesta proposição de definição para o extrativismo, o produto pode ser coletado para o autoconsumo ou para a comercialização local, regional ou nacional.

21 O conceito de UPA está vinculado ao conceito de Sistema de Produção, por conseguinte, as áreas de uso ocasional também estão inseridas no conceito de UPA (ver conceito início do artigo). 
as áreas de uso ocasional. Como consequência desta inclusão, evidencia-se que em determinadas regiões podem existir sistemas de produção difusos, capazes de ocasionar sistemas de produção sobrepostos, quando unidades familiares utilizam uma mesma área de uso ocasional.

Em relação à existência de um sistema extrativista, averiguou-se que tanto o extrativismo vegetal quanto o extrativismo animal possuem conhecimentos acumulados e diversos graus de intencionalidades associados à manutenção e promoção do estoque das espécies exploradas. Portanto, o sistema de cultivo e o sistema de criação devem ser entendidos como gradientes que vão desde o cultivo e criação de espécies domesticadas, aliadas às práticas agrícolas convencionais, até o extrativismo vegetal e animal, com práticas de manutenção e promoção de determinadas espécies.

Por fim, verificou-se uma heterogeneidade associada ao conceito de extrativismo. Esta heterogeneidade está relacionada à origem do produto explorado, ao destino do mesmo ou, ainda, à sustentabilidade da prática. Diante da diversidade de conceitos e da revisão bibliográfica, constatou-se a necessidade de uma definição mais abrangente para extrativismo. Dessa forma, definiuse extrativismo como uma atividade que ocorre na paisagem, independente do seu grau de domesticação, e consequentemente modificará esta paisagem por meio do possível aumento no seu estado de domesticação. Além disso, a espécie explorada não deve ser totalmente domesticada (ver CLEMENT, 1999). Como consequência da exploração contínua de determinadas espécies, podese gerar um acúmulo de conhecimentos acerca das mesmas, fazendo com que extrativistas tenham práticas específicas de manejo para cada espécie explorada. Essas práticas podem se assemelhar cada vez mais com um cultivo ou criação, denotando novamente a noção de gradiente, e buscando negar a ideia de que o extrativismo é apenas a pura e simples coleta de produtos da natureza.

\section{REFERÊNCIAS}

ARAUÚJO, M. Avaliação da biodiversidade em conservação. Silva Lusitana, Lisboa, v. 6, n.1, p. 19-40, 1998.

BALDAUF, C.; HANAZAKI, N.; REIS, M. S. dos. Caracterização etnobotânica dos sistemas de manejo de samambaia-preta (Rumohra adiantiformis (G. Forst) Ching Dryopteridaceae) utilizados no sul do Brasil. Acta Botanica Brasilica, São Paulo, v. 21, n. 4, out/dez., p. $823-834,2007$.

BALÉE, W. The culture of Amazonian forests In: POSEY, D. A.; BALÉE, W. (Eds.). Resource management in Amazonia: indigenous and folk strategies.. New York: New York Botanical Garden, 1989. (Advances in Economic Botany, 7).

Novos Cadernos NAEA • v. 17 n. $2 \cdot$ p. 189-217 • dez. 2014 
BARROS, F. B. Biodiversidade, uso de recursos naturais e etnoconservação na Reserva Extrativista Riozinho do Anfrísio (Amazônia, Brasil). 2011. 223 f. Tese (Doutorado em Biologia da Conservação) - Programa de Pós-Graduação em Biologia da Conservação, Universidade de Lisboa, Lisboa, 2011.

BEHLING, H.; PILLAR, V. D. P. Late Quaternary vegetation, biodiversity and fire dynamics on the southern Brazilian highland and their implication for conservation and management of modern Araucaria forest and grassland ecosystems. Philosophical Transactions of the Royal Society of London. Biological Sciences, v. 362, p. 243-251, 2006. Disponível em: <http://ecoqua.ecologia.ufrgs.br/arquivos/Reprints\&Manuscripts/ Behling\&Pillar_2007_PhilTransRoyalSocB.pdf> Acesso em: 10 jan. 2013.

BELCHER, B.; KUSTER, K. Non-timber forest product commercialization: development and conservation lessons. In: KUSTER, K.; BELCHER, B. Forest Products, livelihood and conservation: case studies of non-timber forest product systems. v. 1 - Asia. 2004. Disponível em: <http://www.cifor.cgiar.org/publications> Acesso em: 5 dez. 2010.

BELCHER, B.; RUÍZ-PEREZ, M; ACHDIAWAN, R. Global patterns and Trends in the use and management of commercial NTFPs: implications for livelihoods and conservation. World Development, v. 33, n. 9, p. 1435-1452, 2005.

BENJAMIN, A. M. da S. Agroextrativismo: sustentabilidade e estratégias na Reserva Extrativista do Rio Cajari, sul do Amapá. 2004. 135f. Dissertação (Mestrado em Agriculturas Familiares e Desenvolvimento Sustentável) - Programa de Pós-Graduação em Agriculturas Familiares e Desenvolvimento Sustentável, Universidade Federal do Pará, Belém, 2004.

BITENCOURT, A. L. V.i; KRAUSPENHAR, P. M. Possible prehitoric anthropogenic effect on Araucaria angustifolia (Bert.) Kuntze expansion during the late Holocene. Revista Brasileira de Paleontologia, Porto Alegre, v.9, n.1, p. 109-116, 2006.

CASTELLO, L. A method to count pirarucu Arapaima gigas: fishers, assessment, and management. North American Journal of Fisheries Management, v. 24, p. 379-389, 2004.

CLEMENT, C. R. Origin, domestication and genetic conservation of Amazonian fruit tree species. In: POSEY, D. A.; OVERAL, W. L. (Org.). Ethnobiology: implications and applications. Proceedings of the First International Congress of Ethnobiology (Belém, 1988). Belém: Museu Paraense Emílio Goeldi, 1990. p. 249-263.

1492 and the loss of amazonian crop genetic resources. i. the relation between domestication and human population decline. Economic Botany, Nova York, n.2, v. 53, p.188-202, 1999.

A lógica do mercado e o futuro da produção extrativista. In: KUBO, R. R. et al. (Org.). Atualidades em Etnobiologia e Etnoecologia. Recife: NUPPEA; Sociedade Brasileira de Etnobiologia e Etnoecologia, 2006. p. 135-150. v. 3.

.; JUNQUEIRA, A. B. Between a pristine myth and an impoverished future. 
Biotropica, v. 42, n. 5 p. 534-536, set. 2010.

; VILLACHICA, H. Amazonian fruits and nuts: potential for domestication in various agroecosystems. In: LEAKEY, R. R. B.; NEWTON, A. C. (Ed.). Tropical trees: the potential for domestication and the rebuilding of forest resources. London: HMSO, 1994. p. 230-238.

CLÜSENER-GODT, M.; SACHS, I. Introdução. In: (Ed.). Extrativismo na Amazônia brasileira: perspectivas sobre o desenvolvimento regional. Paris: Compêndio MAB 18-UNESCO, 1994.

COELHO-DE-SOUZA, G. Extrativismo em área de Reserva da Biosfera da Mata Atlântica no Rio Grande do Sul: um estudo etnobiológico em Maquiné. 2003. $130 f$. Tese (Doutorado em Botânica) - Programa de Pós-Graduação em Botânica, Universidade Federal do Rio Grande do Sul, Porto Alegre, 2003.

COELHO-DE-SOUZA, G.; KUBO, R. R.; MIGUEL, L. de A. (Orgs.). Extrativismo da samabaia-preta no Rio Grande do Sul. Porto Alegre: EDUFRGS, 2008.

DEFFONTAINES, J. P. Analyse du paysage et étude regionale des systèmes de production agricole. Economie Rurale, Paris, v. 98, n. 1, p. 3-13, oct./dec. 1973.

DILLENBURG, L. R. et al. Aspectos ecofisiológicos da regeneração de Araucaria angustifolia. In: FONSECA, C. R. et al. (Org.). Floresta de Araucária: ecologia, conservação e desenvolvimento sustentável. Ribeirão Preto: Holos, 2009. v. 1. p. 57-65.

DUFUMIER, M. Les projets de développement agricole: manual d'expertise. Paris: Karthala et CTA, 1996.

Projetos de desenvolvimento agrícola: manual para especialistas. Salvador: EDUFBA, 2007.

EMMI, M. F. A Oligarquia do Tocantins e o domínio dos Castanhais. 2. ed. rev. ampl. Belém: UFPA/NAEA, 1999.

EMPERAIRE, L.; LESCURE, J.-P. Introdução. In: EMPERAIRE, L. (Ed.). A floreta em jogo: o extrativismo na Amazônia Central. São Paulo: EdUNESP; Imprensa Oficial do Estado, 2000. p. 15-22.

EMPERAIRE, L.; MITJA, D. Bertholletia excelsa, uma espécie de múltiplas inserções. In: EMPERAIRE, L. (Ed.). A floreta em jogo: o extrativismo na Amazônia Central. São Paulo: EdUNESP; Imprensa Oficial do Estado, 2000. p. 109-118.

GUERRA, M. P. et al. Exploração, manejo e conservação da Araucária (Araucaria angustifolia). In: SIMÕES, L. L.; LINO, C. F. (Org.). Sustentável Mata Atlântica: a exploração de seus recursos florestais. São Paulo: SENAC, 2002. p. 85-101.

GUERRA, G. A. D. Efeitos da ocupação urbana no extrativismo vegetal da ilha de Cotijuba. 2. ed. Belém: UNAMA, 2011.

HECKENBERGER, M. J. et al. Amazonia 1492: pristine forest or cultural parkland? Science, v. 301, p. 1710-1714, Sept. 2003.

Novos Cadernos NAEA • v. 17 n. $2 \cdot$ p. 189-217 • dez. 2014 
HOMMA, A. K. O. Extrativismo na Amazônia: limites e oportunidades. Brasília: EMBRAPA/SPI, 1993.

Extrativismo vegetal na Amazônia: limites e possibilidades. In: CLÜSENERGODT, M.; SACHS, I. (Ed.) Extrativismo na Amazônia brasileira: perspectivas sobre o desenvolvimento regional. Paris: Compêndio MAB 18-UNESCO, 1994.

HOUAISS, A.. Minidicionário Houaiss da Língua Portuguesa. 4. ed. rev. e aum. Rio de Janeiro: Objetiva, 2010.

KLEIN, R. M. O aspecto dinâmico do pinheiro brasileiro. Sellowia - Anais Botânicos do Herbário Barbosa Rodrigues, n.12, 1960.

KUSTER, K.; BELCHER, B. Forest Products, livelihood and conservation: case studies of non-timber forest product systems. v. 1 - Asia. 2004. Disponível em: <http:// www.cifor.cgiar.org/publications>. Acesso em: 15 dez. 2005.

LANDAIS, É.; LHOSTE, P.; MILLEVILLE, P. Points de vue sur la zootechnie et sur lês systèmes d'élevage tropicaux. Cahiers dês Sciences Humaines, Paris, v. 23, n. 3-4, p. 421-437, 1987. Disponível em: <http://horizon.documentation.ird.fr/exl-doc/pleins_ textes/pleins_textes_4/sci_hum/24938.pdf>. Acesso em: 15 dez. 2012.

LAPIERRE, J.-W. L'analyse de systèmes: l'application aux sciences socials. Paris: Syros/Alternatives, 1992.

LESCURE, J-P. Algumas questões a respeito do extrativismo. In: EMPERAIRE, L. (Ed.). A floreta em jogo: o extrativismo na Amazônia Central. São Paulo: EdUNESP; Imprensa Oficial do Estado, 2000. p. 191-206.

LESCURE, J.-P.; PINTON, F.; EMPERAIRE, L. O povo e os produtos florestais na Amazônia Central: uma abordagem multidisciplinar do extrativismo. In: CLÜSENERGODT, M.; SACHS, I. (Eds). Extrativismo na Amazônia brasileira: perspectivas sobre o desenvolvimento regional. Paris: Compêndio MAB 18-UNESCO, 1994.

LOPES JUNIOR, A. L., SANTOS, S; M., SABLAYROLLES, M. G. P. O amálgama floresta e agricultura na reserva extrativista Arióca Pruanã. Belém, Novos Cadernos NAEA, v. 16, n. 1, jun de 2013, p. 181-2001, ISSN 1516-6481.

MABILDE, P. F. A. B.. Apontamentos sobre os indígenas selvagens da Nação Coroados dos matos da Província do Rio Grande do Sul - 1836-1866. São Paulo: Ibrasa; Brasília: INL/Fundação Nacional Pró-Memória, 1983.

MACHADO, F. S. Manejo de produtos florestais não-madeireiros: um manual com sugestões para o manejo participativo em comunidades da Amazônia. Rio Branco: PESACRE, CIFOR, 2008.

MACINTOSH, R. P. The background of Ecology: concept and theory. Cambridge: Cambridge University Press, 1985.

MATTOS, A. G. Caracterização das práticas de manejo e das populações de ervamate (Ilex paraguariensis A. Sant. Hil) nativa em exploração no planalto norte catarinense. 2011. 178f. Dissertação (Mestrado em Recursos Genéticos Vegetais) - 
Programa de Pós-Graduação em Recursos Genéticos Vegetais, Universidade Federal de Santa Catarina, Florianópolis, 2011.

MATTOS, J. R. de. O pinheiro brasileiro. 2. ed. Lages: Artes Gráficas Princesa, 1994. v. 5 .

MAZOYER, M.; ROUDART, L. História das agriculturas do mundo: do neolítico à crise contemporânea. Lisboa: Instituto Piaget, 2010.

MAZOYER, M.; MIGUEL, L. de A. A abordagem sistêmica no âmbito das ciências agrárias. In: MIGUEL, L. de A Dinâmica e diferenciação de sistemas agrários. Porto Alegre: EdUFRGS, 2009. p. 17-25.

MIGUEL, L. de A.; MAZOYER, M.; ROUDART, L. Abordagem sistêmica e sistemas agrários. In: MIGUEL, L. A. Dinâmica e diferenciação de sistemas agrários. Porto Alegre: EdUFRGS, 2009. p. 11-17.

MORIN, E. A organização (do objeto ao sistema). In: O método 1: a natureza da natureza. 2. ed. Porto Alegre: Sulina, 2005.

NEUMANN, R. P.; HIRSCH, E. Commercialization of non-timber forest products: review and analysis of research. Bogor: CIFOR/FAO, 2000.

PETRERE Jr., M. Notas sobre a pesca dos índios Kayapó da aldeia de Gorotire, Rio Fresco, Pará. Boletim do Museu Paraense Emílio Göeldi, Belém, v. 6, n. 1, p. 5-17, 1990.

PRÓ-JOVEM. Arco Ocupacional Agroextrativismo: manual do educador. 2. ed. Brasília: Ministério do Trabalho e Emprego, 2008.

PINZÓN RUEDA, R.. [200-?] O Neoextrativismo ou agroextrativismo. Disponível em: <http://www.ibama.gov.br/resex/historia.htm>. Acesso em: 1 abr. 2013.

POSEY, D. A. The importance of semi-domesticated species in post-contact Amazônia: effects of the Kayapó Indians on the dispersal of flora and fauna. In: HLADIK, M. C. et al. (Org). Food and nutrition in tropical forest: biocultural interactions and applications to development. Paris: Unesco, 1993. (MAB serie,. v. 3).

POSEY, D. A. Etnobiologia: teoria e prática. In: RIBEIRO, B. G. (Coord.). Suma Etnológica Brasileira: 1 Etnobiologia. 3. ed. Belém: EDUFPA, 1997. p. 1-15.

PUCHALSKY, Â.; MANTOVANI, M.; REIS, M. S. dos. Variação em população naturais de Araucaria angustifolia (Bert.) O. Kuntze associada a condições edafo-climáticas. Scientia Forestalis, Piracicaba, v. 70, p. 137-148, 2006.

QUANG, D. V.; ANH, T. N. Commercial collection of NTFPs and households living in or near the forest: case study in Que, Con Cuong and Ma, Tuong Duong, Neghe An, Vietnam. Ecological Economics, v. 60, p. 65-74, 2006.

RÊGO, J. F. Amazônia: do extrativismo ao neoextrativismo. Ciência Hoje, v. 147, 1999. Disponível em: <http://cienciahoje.uol.com.br/view/349>. Acesso em: 21 nov. 2005. 
REIS, M. S. dos; LADIO, A. Paisajes con Araucarias en Sudamérica: construcciones culturales pre-colombinas y del presente para producción de alimento. In: NAVARRO, V. Y.; ESPINOSA, S. Paisajes culturales: memorias de las Jornadas de reflexión acerca de los paisajes culturales de Argentina y Chile, en especial los situados en la región Patagónica. Rio Gallegos: AR. ICOMOS/UNPA/UMAG, 2012. p. 224-244.

REITZ, R.; KLEIN, R. M. Araucariceae: flora ilustrada catarinense. Itajaí: Herbário Barbosa Rodriguês, 1966.

RIBAS, R. P.; SEVERO, C. M.; MIGUEL, L. de A. Agricultura familiar, extrativismo e sustentabilidade: o caso dos "samambaieiros" do litoral norte do Rio Grande do Sul. Revista Economia e Sociologia Rural, Brasília, v. 45, n. 1, jan./mar., 2007.

SEBILLOTE, M.. Systèmes de culture, um concept opératoire pour lês agronomes. In: COMBE, L; PICCARD, D. (Org.). Les systèmes de culture. Paris: INRA, 1990. p. 165-196.

SILVA JUNIOR, A. L. Quando os paus de fruta da mata viram plantas: o amálgama entre agricultura e floresta na Resex Arióca Pruanã, Oeiras do Pará. 2012. 141f. Dissertação (Mestrado em Agriculturas Amazônicas) - Programa de Pós-Graduação em Agriculturas Amazônicas, Universidade Federal do Pará, Belém, 2012.

SILVA NETO, B.; BASSO, D. Aplicação da teoria dos sistemas agrários para a análise da agricultura do Rio Grande do Sul. In:

Sistemas agrários do Rio Grande do Sul: análise e recomendações de Políticas. Ijuí: EdUNIJUI, 2005. p. 17-24.

SOARES, R. V. Considerações sobre a regeneração natural da Araucaria angustifolia. Floresta, Curitiba, v. 10, n. 2, p.12-17, 1979.

STEENBOCK, W. Domesticação de bracatingais: perspectivas de inclusão social e conservação ambiental. 2009. Tese (Doutorado em Recursos Genéticos Vegetais) Programa de Pós-Graduação em Recursos Genéticos Vegetais, Universidade Federal de Santa Catarina, Florianópolis, 2009.

SUÁREZ, J. E. A.; COELHO-DE-SOUZA, G.; MIGUEL, L. de A. Extrativismo da samambaia-preta e a geração de renda para a agricultura familiar. In: COELHO-DESOUZA, G.; KUBO, R. R.; MIGUEL, L. de A. (Org.). Extrativismo da samabaiapreta no Rio Grande do Sul. Porto Alegre: EdUFRGS, 2008, p. 139-156.

VILLARET, A. E1 enfoque sistémico aplicado al análisis del medio agrícola. Sucre: PRADEM/CICDA, 1994.

WIVES, D. G. Funcionamento e performance dos sistemas de produção da banana na microrregião do litoral norte do Rio Grande do Sul. 2008. $164 f$. Dissertação (Mestrado em Desenvolvimento Rural) - Programa de Pós-Graduação em Desenvolvimento Rural, Universidade Federal do Rio Grande do Sul, Porto Alegre, 2008. 
